\title{
Stagnation and Decay in sub-Saharan Africa: Dialogues, Dialectics and Doubts
}

\author{
Caroline Allison and Reginald Green
}

... fragments of our lost kingdom ...

Here the stone images

Are raised, here they receive

The supplication of a dead man's hand

Under the twinkle of a fading star.

\section{T. S. Eliot, The Hollow Men}

Output per person rose more slowly in subSaharan Africa than in any other part of the world, particularly in the 1970s, and it rose more slowly in the 1970 s than in the $1960 \mathrm{~s} \ldots$. The tragedy of this slow growth in the African setting is that incomes are so low and access to basic services so limited... Now, against a backdrop of global economic recession, the outlook for all less-developed nations - but especially for the sub-Saharan region - is grim.

Accelerated Development in sub-Saharan Africa

[World Bank 1981: 3,4]

Shape without form, shade without colour, Paralysed force, gesture without motion; .. .

What are the roots that clutch, what branches grow Out of this stony rubbish?

\section{T. S. Eliot, The Hollow Men/Gerontion}

\section{Request to Report: Genesis of an Agenda Accelerated Development in sub-Saharan Africa: an Agenda for Action [World Bank 1981] was born in response to a 1979 Request of the African Governors of the World Bank for a review of the cause and potential cures for the dim economic prospects which they believed confronted their economies. It appeared in the autumn of 1981 as the first comprehensive ideological and programmatic manifesto setting out the post-McNamara Bank's response to lagging development (in many cases distintegration), in the context of rising global economic disorder and deepening industrial economy recession.}

The African official response has been mixed: welcoming calls for more aid, but politely querying whether outside expert advice was always part of the solution rather than the problem; agreeing on the dismal record of the late 1970 s, but wondering whether it was not both less uniformly gloomy and more the result of external shocks than the Report suggests; agreeing on the need to put higher priority on raising production and exports, but expressing some scepticism about the rather simple market forces, private sector, export led model of the Agenda. Privately, many have been more sharply critical: 'we asked for bread and they threw a stone at us' was the sad reflection of a senior economic analyst of a relatively conservative African state with a good 1970s performance record.

\section{Some Issues of Presentation and of Principle} Several characteristics of the Report may help to explain this response. First, its style is both ex cathedra and minatory. No signs of self-doubt as to the wisdom of the analysis and prescription presented intrude on the reader (even when they contain apparent major inconsistencies). Further, there is a clear implication that the Bank will only support programmes in subSaharan African (SSA) states which adopt its Agenda, and will seek to coordinate bilateral donors to do likewise. The Bank does itself and its audience less than justice. In face to face discussion and dialogue (and in internal debates) Bank personnel show far more uncertainty and doubt, and display greater realisation that actual decisions are among complex, imperfect choices with, at best, a moderately wide range of possible outcomes. Furthermore, at least in the past, Bank flexibility in adapting projects and programmes to actual contexts, and 'pure' economic calculations to political economic realities has been real, if uneven. Its potential for mobilising other agencies has been used as a carrot rather than a stick.

Second, the analysis and prescription of the Report are riddled with rather sweeping generalisations and inconsistencies. This is partly the result of the normal operation of an institutional committee's editing of an 
outside consultant's draft. ${ }^{1}$ Professor Eliott Berg, the main consultant, has a more rigorous free competitive market force, comparative advantage led, neo-liberal political economic world-view than that reflected in the final report. While one may suspect that some of the changes were made by softening proposals, the majority appear to have taken the form of additions based on existing Bank commitments (eg food production, manpower development, population planning) even when these seem to contradict the main thrust of the Agenda. Second, the Bank's typical style of using general background analysis, broad principles and thumbnail case sketches to arrive at concrete policy proposals lacks any clear articulation from background analysis up to the general principles, or down from them to the policy proposals. ${ }^{2}$ This can raise difficulties of overgeneralisation, not quite fitting any actual case, and is so lacking in logical rigour as to give maximum room for initial premises to be backed by selective use of evidence, and then deployed directly to back the writers' own preferred lines of action without serious analysis of practicability or prudence.

Third, no reader of Agenda is likely to suspect the Bank of ever having made any mistakes other than those based on inaccurate technical data inputs or misplaced faith in the rationality and expertise of recipient governments. Yet - to cite two examples in calling for highway project analysis and support to include maintenance costs (pp 106, 126) and in avoiding the creation of parallel, autonomous, expert staffed administrative and policy units outside the domestic decision-taking structure [pp 130, 132] the Bank is reversing its own 1970s advice with a vengeance. ${ }^{3}$ This is damaging on two counts: to admit to analyse - as well as to reverse - past mistakes is often a necessary first step toward avoiding future ones; to avoid all responsibility for the results of policies and projects in which one is directly implicated not only undermines the credibility of new proposals, it generates animosity on the part of those who know their case histories, which impedes rational consideration of any proposals. Learning and convincing others both require overt recognition of

\footnotetext{
${ }^{1}$ One co-author has experienced this process from both sides - in academia and government and as a consultant to international agencies. It has its virtues, but achieving rigorous analysis, clear priorities or total internal consistency are rarely among them.

${ }^{2}$ This is in part inevitable in attempting to work from concrete analysis to organising principles and back to concrete proposals for a large number of cases with severe space constraints. It is exacerbated by the Bank's desire to avoid any serious analysis of the nature of and distinct divergencies among African states - a desire which is understandable, but leaves the political and the concrete out of political economy in a way which Smith, Ricardo and Mill would have found as unsatisfactory as Marx and Lenin.

${ }^{3}$ One co-author has been in several country negotiations on the Bank precisely on these issues. On at least one occasion - wrongly he now believes - he in fact was a proponent of the creation of parallel policy administrations.
}

fallibility. ${ }^{4}$ Similarly, to criticise decisions ex ante is not always the best way to understand how they came to be made, and how to avoid similar types of 'good $e x$ ante'/'bad ex post' choices today. The prospects for the world economy in the 1970s always differed (to $O E C D$ states as much as to African) from the way events actually turned out. Choices apparently based on optimism tempered by prudence have in the event often proved very wasteful indeed. With the greater uncertainty - as well as poorer ex ante projections - surrounding the world economy's evolution in the 1980s, this lesson, on the costs of being 'certain', deserves careful reflection in terms of its implications for action.

Fourth, while certain modifications are made in the direction of human investment and basic services (but with user charges and partial privatisation) and of selective, public sector, infrastructure and private sector incentive oriented state policy interventions, the basic doctrine of the Report is that of economic (and political) neo-liberalism. Access to basic needs, elimination of absolute poverty and distribution are taken off the Agenda. They are treated, at best, as the by-products of maximising growth by selective allocation of resources to areas and actors with high short-term output potential and over-riding concentration on (also short-term?) profitability. From this perspective closer integration of SSA's domestic economies (already among the world's most open in terms of import to GDP ratios) into the world economy is seen as self-evidently desirable, because of the poor growth prospects for the major industrial economies and for international trade. The assertion [p 1] that Agenda builds on the Lagos Plan of Action [OAU 1980], which calls for SSA national and regional integration and relatively less dependence on an international economic environment, is with the exception of the Report's support to regional integration [pp 118-19] simply not accurate; the reverse would be nearer the truth.

\section{Is the Agenda Important?}

These four characteristics of the Report outlined above are not all of a kind. The first three raise questions as to completeness, consistency and direct applicability to specific cases (a doubt the Report

\footnotetext{
${ }^{4}$ This is not to say that the Bank was either alone, careless or ill-intentioned in cases of advice which have come unstuck. One co-author must acknowledge having supported such Bank advice in a number of cases he now perceives as errors (eg cutting Tanzanian grower prices for maize in the early 1970s, selecting tea and tobacco as 'growth pole' crops). Nor, indeed, is it to argue that the Bank necessarily has a worse record than other sources of advice. But it has been influential and in a number of cases influential in securing the adoption of policies, the creation of institutions and the implementation of projects now rightly criticised (often, though not always, by the Bank).
} 
occasionally - eg on pv - shares), but not necessarily as to the overall sweep of the data, analysis and conclusions. Their greatest damage may lie in the possibility of preventing African and other critics reading and reflecting without a bias against the proposals because of their tone and style of presentation. The fourth is different. Economic neoliberalism as a credo (as opposed to a number of the measures contained in neo-liberal programmes) is contentious analytically, disputed empirically and ultimately accepted or rejected on normative, selfinterest, and theological rather than pragmatic, public interest, and programmatic grounds. ${ }^{5}$

None of these comments mean that the Report is unimportant, or that it should or can be overlooked. It rests on a major data collection exercise. Its presentation of the 1960-79 economic history of Africa is a serious attempt at description and analysis. It has a central organising economic model linked to a political economic ideology of some real power and some past and present capacity to perform. It is the only major general policy-oriented analysis of SSA's economic crises, and what might be done about them. The Lagos Plan [OAU 1980] is not short-term, nor detailed in terms of policy orientation. African national strategy studies are - by definition - not regional, and rarely present overall historical and political economic perspectives explicitly. ${ }^{6}$ Any major set of World Bank proposals backed by its influence, technical capacity, funds and influence on other sources of finance will have a significant impact on events. This is especially likely in the case of this Report, which is directed to the group of countries which are economically weakest, currently most dependent on external resource transfers, and historically most disposed to accept (or least able to reject?) external advice backed by economic influence. Whatever academic and African official analysts think of it, Accelerated Development will be a substantial force for good, for evil, or - more probably - for a mixture of both.

The main body of this Bulletin consists of a more detailed examination of selected key themes and sectors from the Report. What follows here is a brief

\footnotetext{
${ }^{5}$ This is, of course, true of any broad political economic perspective and of overall strategies derived from it. The same comment could be made about Marxian, pragmatic welfare capitalist (eg Keynesian or Brandtian) and neo-social democratic (eg basic needs) perspectives, although in these the public interest (or externalities surrounding self interest) have greater weight than in neo-liberalism.

${ }^{6}$ African critics may - with a not inconsiderable degree of fairness - suggest that they are also viewed with reservations internationally (and even domestically within Africa) precisely because they are African. Whether this is based on a variant of 'if you're so smart why aren't you rich?', on cultural or racial prejudice, or simply because Africans, like women, are often 'invisible' to many analysts and administrators, is less clear, and probably varies from case to case.
}

resumé of its overall analytical presentation and of its prescriptions for action.

\section{Descriptive and analytical foci}

Four principal themes link the Report's empirical evidence, descriptive examples and analysis:

First, SSA economies (on most criteria) performed only moderately well in the 1960 s and much worse in the 1970s. Prospects for the 1980s are even bleaker. Indeed, a decline in per capita GDP is likely on present trends for the $\mathbf{2 4}$ low income countries;

Second, the world economic environment for SSA in the 1970s was mixed - with some very negative shock impacts - but will be less favourable in the 1980s. African governments must adjust policies to this bleaker climate and capture the opportunities of comparative advantage-based, export oriented growth, which most of them failed to do in the 1970s;

Third, SSA performance in respect to overall economic and export growth is significantly worse than that of other Third World regions and deteriorated more sharply in the 1970s. While part of this may be structural - eg on export mix, excluding oil, dominated by commodities with low global demand growth - much of it is not - eg decline in share of world markets - for most main exports in the 1970s; after a mixed, but on balance, positive performance on this count in the 1960s;

Fourth, the basic cause of deteriorating SSA economic performance lies in African economic policy and practice. Policies have been inward-looking (biased against exports), elitist (interventionist and overextended), inconsistent in formulation and unsatisfactory in management, biased against agriculture and against the private sector. In particular, overvalued exchange rates, quantitative trade restrictions, excessive government spending and lack of incentives have hampered economic growth.

Each of these descriptions/lines of argument contains very substantial elements of truth, and a good deal of common ground among the Report's authors and advocates on the one hand, and sceptics or critics on the other. None, however, is quite as clearcut and simple as the Agenda seems to suggest.

First, growth performance - while generally unimpressive - has been very diverse among countries and over time. In 1977-78 (ie before the 'second oil crisis') the general impression was of sustainable recovery to 1960 s -early 1970 s growth levels after weathering the 1973-75 crisis.

Second, while the need to adjust to a worsened external setting is unquestionable, the Report arguably understates the weight of external factors in worsened 
performance, especially in 1979 (and a fortiori since). This is relevant in assessing how much of the worsened performance (and prospects) is related to basically unsound policies; how much to policies overtaken by events; and how much to the lags accompanying new policies, or to accelerating external shocks swamping policy responses.

Third, taken as a region, SSA has the worst 1970s growth performance absolutely and relative to other regions. The same is true for 'low income countries' (as defined by the Bank). However, within the 'least developed' and 'landlocked' categories (as defined by the UN) the African economies, which are a majority in both groups and comprise a majority of SSA countries, on balance have somewhat above average performance.

Fourth, the fact that a number of policy and management errors classifiable in each of the categories cited do exist, proves neither the generality of these failings, nor that the Report's categorisation is the only possible one. For example, one could argue on the evidence that inadequate and inadequately coordinated state policy - especially in respect to exports - and too liberal and too unselective use of credit licensing of imports were key mistakes, rather than too much government and too many barriers to imports. Similarly, the government expenditure levels and growth rates relative to GDP do not correlate with economic performance [as the Report admits on $p 36$ ]. Further, a substantial number of SSA economies adjusted their policies promptly to meet the 1973-75 crisis, and achieved rapid recoveries of growth and external balance up to the 1979 'second oil crisis'. This casts some doubt on any interpretation of overall policy weaknesses as the central underlying cause. Finally, policies in African states vary rather more widely than the Report seems to recognise, but performance on purely economic criteria (as opposed to distributional and access to public services tests)

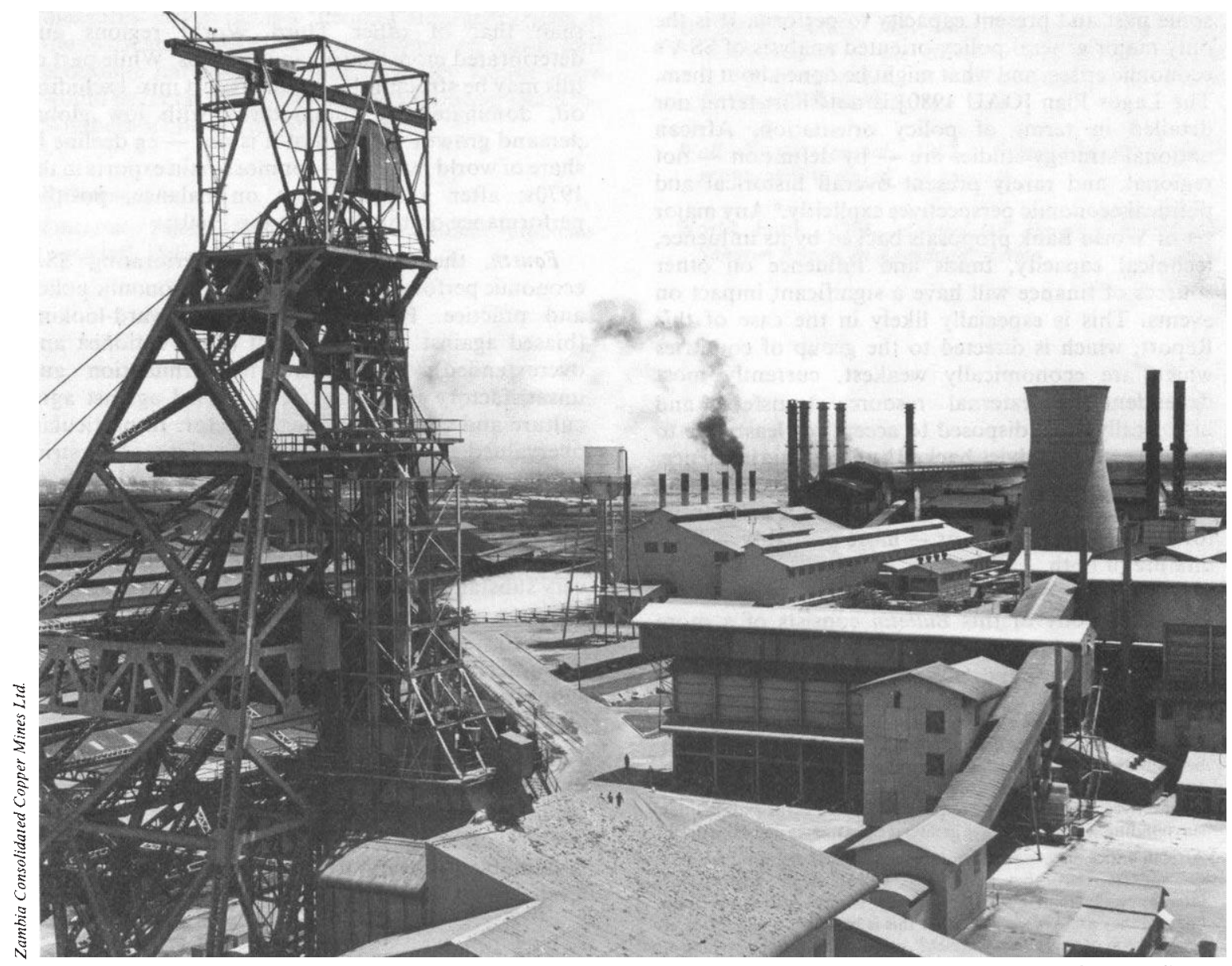

Mining is critical to exports, employment and government revenue in several African economies - and has fared badly since 1975. (Mufilira copper mine, Zambia) 
does not seem to correlate at all closely with these differences.

None of this alters the need for clearer priorities, more effective coordination, economy of scarce resources, or the need to adjust to a nastier world than that of the 1960 s or even the 1970s. In particular it does not alter the fact that during 1976-78 many SSA economies wrongly believed (as did the OECD and the World Bank) that the international economy was returning to early 1970s patterns and trends. However, questions do arise as to what the basic nature of policy errors and the appropriate changes to be made are.

\section{Patterns of Prescriptions}

The Agenda contains a positive forest of proposals which vary in terms of generality, individual importance and their interaction with other proposals. A number are fairly clearly desirable on almost any criteria; others are either generally debatable or relevant to certain contexts, but not to others. A clear set of priorities - below the very general level - and a coherent presentation of structure, interrelationship and consistency are harder to find in the Report. The trees do, in this case, tend to conceal the parameters of the forest. However, using repeated references and the degree of stress placed on cases cited, ten clusters appear to dominate the proposals for action.

First, that there should be less (or at least, less expansion of) state activity in traditional areas, with the exception of economic infrastructure to serve the private sector. In the case of basic services, universal free access is at least implicitly rejected while more privatisation of health and education, and more user charges for all services (somewhat incongruously

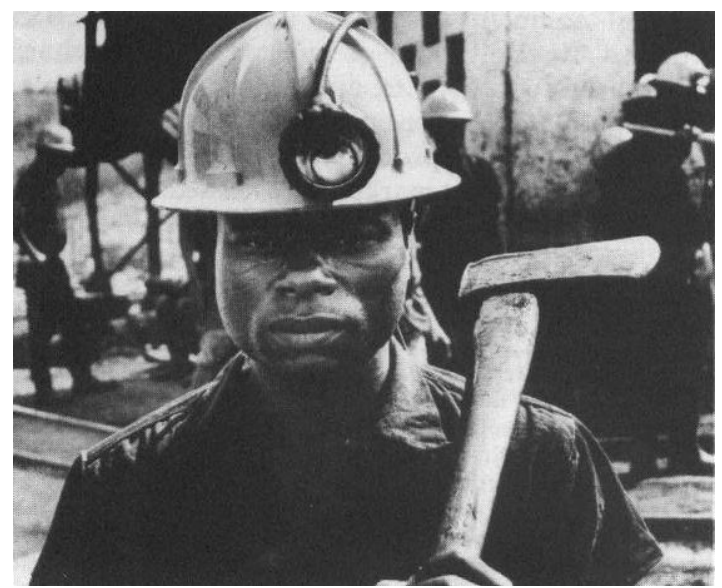

African miners engage in arduous work for quite limited rewards. (Mozambican miner) packaged as part of an appeal for participation by local communities in decision-taking) are stressed. Related to the cutback in state activity is the second focus: curtailment of parastatal (especially directly productive) activity in favour of dynamic, flexible private sector entrepreneurs. Given the long list of debacles cited, it is not clear why reform, consolidation and reduction of roles - enforced by free competition - rather than wholesale denationalisation, is advocated. However, the number of specific proposals for privatisation (from drugs and seeds to basic foodstuffs) and the deep conviction that the private sector can always outcompete the public, may add up to the same thing.

Third is greater emphasis on export expansion, linked to agriculture as a means of raising peasant earnings and foreign exchange, and to industry as a means of increasing competitive tests of efficiency and laying a basis for medium-term diversification of exports. This emphasis is not simply a pragmatic response to the appalling imbalance of payments crisis confronting most SSA economies, with exports in a majority of cases covering less than two-thirds of imports. Rather, it is part of a general fourth theme for more integration into the world market on the basis of short-run comparative advantage unhampered by government restrictions.

Fifth, as a necessary corollary to the external integration prescriptions, is a call for reduced emphasis on self-sufficiency, apparently in food (although the Report appears equivocal on this) and certainly in manufactures. Protection is seen as demonstrating inefficiency, and arguments about building up new long-term comparative advantage; insuring against global economic uncertainties; or utilising otherwise totally unemployed resources ('some production is better than none') as quibbles or rationalisations of inefficiency. The need for incentives to raise the levels and alter the make-up of production is the sixth important theme. Price incentives and market forces to set them are given primacy. Noneconomic incentives are specifically put to one side as somehow beyond development analysts' proper concerns (or perhaps merely their knowledge?). Certain other economic incentives (eg actual buyers, inputs, goods to buy, transport) are also, quite rightly, stressed, albeit perhaps not enough relative to price.

Seventh, the need for more middle and high-level trained personnel (to provide greater 'technical expertise') is stressed. Somewhat oddly, given the proposals on government spending cuts, so is the need for more primary education. In addition to personpower, the eighth focus is knowledge and data (ie applied research, financial reports and statistics), which are cited as critical areas both for accelerated 
growth, and for more selectivity and simplification to speed up the availability of critical technological breakthroughs and data to manage operations, monitor performance and prepare policies.

Ninth, the need to set priorities, articulate policies and programmes from them in a consistent manner, coordinate implementation and review and allocate resources in accordance with the coordinated priority, from policy to project package, is heavily stressed at several points. Surprisingly, its own articulation seems rather vague and fragmentary, and to betray a certain lack of first-hand knowledge of policy and decisiontaking practice in SSA (or almost anywhere else).

Finally, the necessity of more external donor involvement is made the subject of an entire chapter, plus references elsewhere. Concessional financial flows should be doubled, made more flexible and related more to policies and less to projects. Aid should be backed by policy involvement de facto or de jure in policy/programme compacts like Bank Structural Adjustment, and IMF stabilisation programmes. These are preferably to be coordinated by the Bank and directed only to countries accepting the Agenda.

Acceptance (merited in many cases) or rejection (also merited in some) ${ }^{7}$ of specific proposals is different from and - at least in the Report's own terms secondary to consideration of the merits and limitations of the main clusters. If these are accepted, most of the specific proposals follow. If they are rejected, the Agenda requires basic revision even if many components taken separately remain the same.

First, it is clear that most SSA states must live more frugally. This may, however, entail raising more taxes and using revenue more effectively, rather than cutting back on functions which are already at dangerously low levels from both economic and social points of view. The bland abstraction from distribution issues and the failure to specify realistically who else could, and would, provide which services for whom, is breathtaking. This applies also to the second cluster relating to public enterprises - whose actual performance is far more varied than is suggested in the Report, and by no means always inferior to that of the private sector. In many cases the only plausible answer is - private foreign enterprise. Perhaps deliberately, the reduced roles posited for public enterprise (eg buyer and seller of last resort and guarantor of interyear supplies in basic foods) are by their nature lossmaking, and would presumably be used as a basis for

\footnotetext{
This is hardly a severe criticism - any list of about 500 specific proposals will contain some which are not fully thought out, subject to negative side effects, impracticable, eccentric or even dotty.
}

subsequent criticisms of their 'efficiency' (defined in enterprise profit terms).

The third cluster - increased priority to exports - is valid. Many African countries have no coherent export strategy, nor policy and programme articulation to implement one. ${ }^{8}$ The problem is how? The targets set in the Report are not feasible on the basis of present or identified future export mixes. Neither growth in primary product demand nor price elasticity data, nor the limits of the past and of the new protectionism to neo-NICery allow any other conclusion. In any event, the need for more exports does not necessarily lead to the fourth theme, advocacy of a free trade/unhampered comparative advantage model. Africa is objectively the most (and most unilaterally dependent) integrated region in the world economy. Historically, escape from low level, free trading dependence has normally involved selective, partial withdrawal and intervention to promote exports at least partly based on different, developed comparative advantage, as in Japan and South Korea.

Given the poor export prospects; the historic record of new export bases - especially in manufacturing being built-up behind protective barriers; and the present global level of excess capacity, which suggests that deprotection would release resources to unemployment, the fifth cluster of reduced self-reliance is at best risky and at worst a recipe for mass starvation. This is in no way to deny that many inefficiencies are committed and many special pleadings rationalised (not least by, and on behalf of, the foreign private sector as in Kenyan and Ivoirienne textiles) in the name of risk avoidance and long-term development. These should be reduced (or rooted out), but their existence does not prove that Japan was wrong. Nor does it reverse the fact that import liberalisation and attempts to shift industry and agriculture toward global competitiveness (as advised by the Bank) tripled Mexico's ratio of imports to GDP; sharply increased food deficits; and played a central role in precipitating the present crisis. More incentives to produce (and to produce products with plausible domestic or export markets) are needed, as stressed in the sixth cluster. Whether the free market - especially in conditions of massive imperfection, severe crisis and generalised restrictive practices as in SSA today -

\footnotetext{
${ }^{8}$ A possibly extreme, but hardly unique, example is Tanzania which had developed fairly clear and coordinated priorities with some articulation to policies and programmes in most other sectors but had no serious strategy for exports until 1980-81. Prior to that, a clutter of uncoordinated micro-initiatives, projections based on estimating future results not seeking to alter or manage them and occasional partial sectoral programmes officially endorsed but not backed by political prioretisation, policies or resource allocations contrasted oddly with very difficult approaches to credit and foreign exchange management, industrial development, expansion of basic services or even reduction of economic inequality.
} 


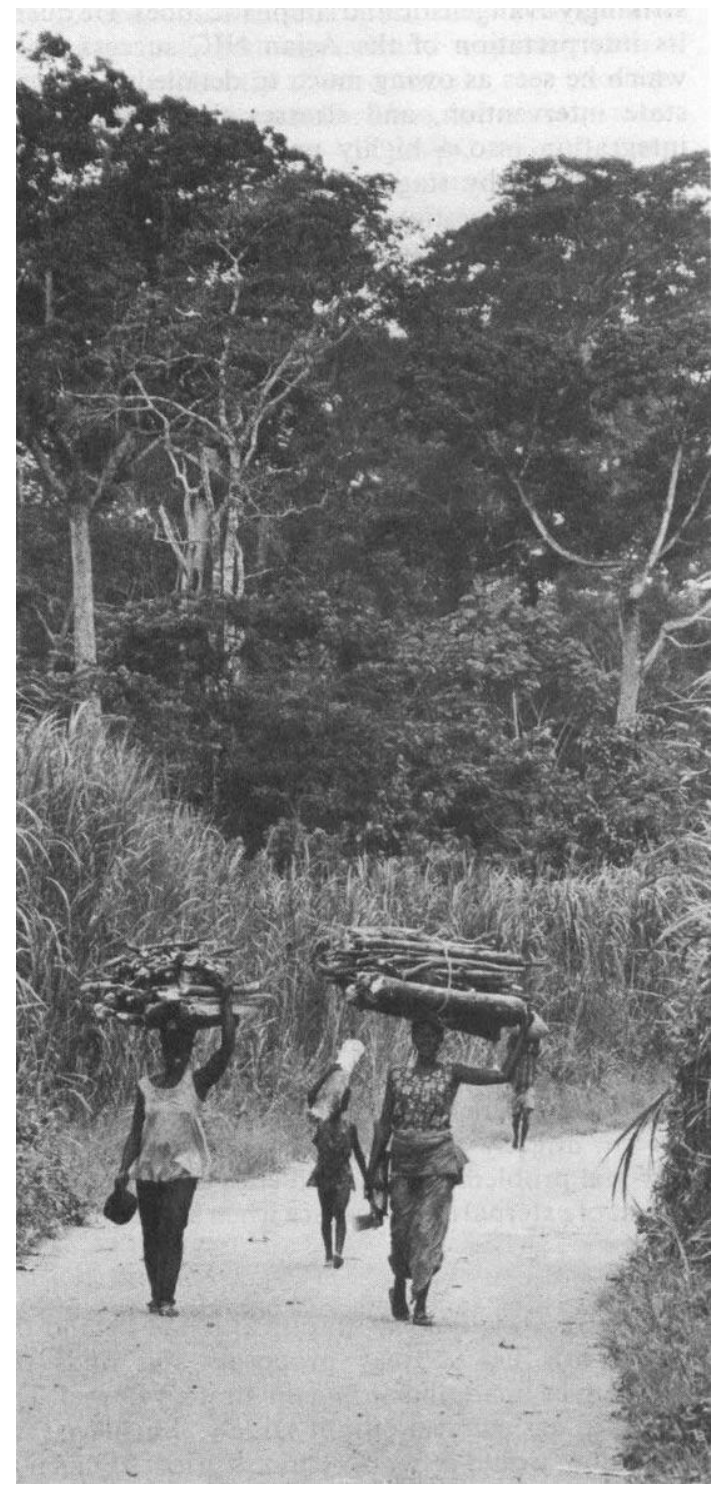

an provide economic incentives without market management oriented state intervention is a different question. So is the exclusion of many apparently relevant incentives, for example, access to health and education, reduction of time spent gathering fuel and water.

The seventh and eighth clusters are clearly broadly correct - more educated personpower, more applicable knowledge and reasonably accurate data more promptly are priorities. Here it is the micro proposals which seem rather ill thought through. Middle level personpower - usually scarcer in SSA than high level ${ }^{9}-$ is not treated systematically and the accounting cadre (a sine qua non for effective

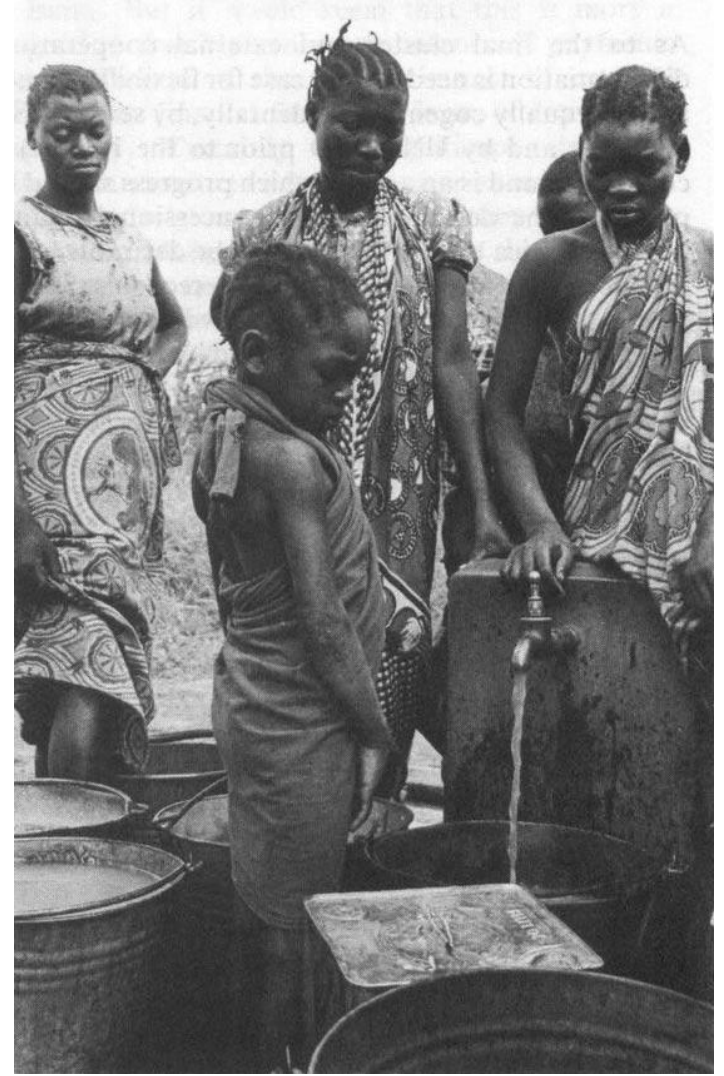

Wood gathering and water carrying are a major burden on African women's time and health. Appropriate improvements have high economic incentive as well as human impact on rural communities. (Women wood carriers in Ghana and village water project in Tanzania)

enterprise and for timely evaluation and policy reform) is not cited as a special priority.

The ninth cluster of clearer strategic priorities more coherently articulated, coordinated and backed by resource allocations is vital. This is true whatever agenda any African state adopts. To plan is to choose and so is to manage. The fact that the same criticism applies to almost all states whether capitalist

\footnotetext{
${ }^{9}$ This is sometimes disguised by the fact that senior personnel have to do their own middle level work (or fail to function because it is not done) which often gives an outsider the impression that the gap is at or near the top, not in the middle of the continuum from unskilled worker to senior manager.
} 
industrial, socialist industrial or developing, does not alter this, although expectations may be tempered.

As to the final cluster and external cooperation, differentiation is needed. The case for flexibility (made at least equally cogently, incidentally, by several SSA countries and by UNCTAD prior to the Report) is compelling and is an area in which progress should be possible. The doubling of real concessional finance flows to Africa over the 1980s may be desirable but it will not happen, as the Bank must recognise. ${ }^{10}$ The proposal for greater donor policy involvement would be desirable if donors listened to and learned from the African side more; were less ready to assert unchallengable wisdom (and to seek to enforce it); and view past mistakes with more humility. These characteristics are not very evident in the Report. As for reorganising bilateral aid around core Bank and Fund programmes, views on that will hinge largely on the readers' views as to the accuracy, practicability, political acceptability and human desirability of their increasingly interlinked world views. However, even supporters of those world views may doubt whether the Bank's apparent aspiration to become SSA's (and the Third World's) planning ministry and Platonic Guardians is in its own best interests or anyone else's.

\section{From General to Sectoral and Case Study}

Many of these points have been drawn from and are elaborated further in the series of more specialised examinations of particular aspects of the Accelerated Development Report which made up this issue of the Bulletin.

Philip Daniel examines the overall reformulation of Bank approaches to development and its central instrumental focus for ensuring that these approaches are implemented in SSA. He recognises the seriousness and importance of the Report as a contribution to discussion and endorses the moves toward advocacy of greater flexibility and overall coherence in concessional resource transfers. Nevertheless he sees a danger of structural adjustment loans becoming a means for fitting diverse economies to a procrustean bed many of whose components appear to be neither so clearly the right ones nor so generally applicable as the Report seems to believe.

Manfred Bienefeld characterises Accelerated Development as a reassertion of the virtues of market forces in

\footnotetext{
${ }^{10}$ There is every reason for the Bank to argue the case for increased concessional finance even when prospects are bleak - at the worst it may help limit cuts in real transfer levels. The problem is that the Report appears to hold out these desirable levels as attainable and a basis for planning - precisely the type of unreal targetry and allocation of unreal resources the Bank (rightly) criticises as indulged in by many SSA states.
}

strikingly evangelistic and simplistic tones. He queries its interpretation of the Asian NIC success stories which he sees as owing much to detailed, persuasive state intervention, and stresses the risks of close integration into a highly unstable world economy characterised by stagnation and unemployment. In addition, he questions the past record of external advice in Africa and asks how many decisions regarded as wrong in retrospect could have been recognised as such before the crises of $1973-75$ and 1979 to date.

Christopher Colclough reviews the evidence on the scale and effectiveness of government activity in Africa. He finds expenditure to be no higher relative to GDP than elsewhere, and viable alternatives to state action (apart from foreign firms) to be lacking in many cases. The Agenda items on privatisation and charges for basic services raise both distributional and efficiency questions which the Report does not face squarely.

Reginald Green reviews the Report's analysis of and prescriptions for the faltering core agricultural sectors of most SSA economies. While identifying a broad area of common ground, he questions both the sweeping nature of some generalisations and the balance of emphasis among proposed remedies. In particular he queries the practicability of raising real purchasing power per unit of agricultural output, and the relatively low emphasis placed on other material incentives which may often be at least as critical. He warns against the assumption that there are clear, known, directly applicable answers to many of the very real problems posed, and cites the rather mixed record of external expert advice when acted on by SSA states.

Martin Godfrey looks at empirical issues behind the export oriented strategy proposals and finds the targets to be unattainable and the strategy flawed. The proposed agricultural output targets, if achieved for the region, would probably depress prices so much as to reduce earnings. The industrial export targets cannot be met in the 1980s because African industries have not had the firm, protected, home market based, several decade long pre-export period that has characterised most late entrants into the manufactured exports market. Nor would trade liberalisation now help build such a base; it would rather cause general de-industrialisation.

Charles Harvey reviews the 1970-81 economic policy and performance of Malawi, a state usually believed to have followed the type of approach advocated in the Report and, thereby, to have avoided economic crises. He finds that the keys to its 1970 s economic and export growth were the systematic erosion of real wages and 
prices paid to smallholders, and the use of marketing board surpluses and bank lending to expand estate agriculture. The current account balance. has deteriorated over the decade - very sharply since 1978 - while both GDP and export growth have declined to near stagnation. In addition the recurrent budget has, for the first time, gone into unmanageable deficit. Nevertheless Malawi has maintained basic food self-sufficiency. Overall the problems and prospects are so similar to those of other African countries that some questions are raised as to how adequate - or even viable in the long run - the Agenda's proposals are.

Stephany Griffith-Jones reflects on the Report's probable results if implemented, in the light of Chile's experience following the implementation of what she sees as a broadly similar political economic world view. The implications are rather daunting as they include a sharp initial fall in output; substantial permanent destruction of large sub-sectors of industry and agriculture; higher unemployment, and worsened income distribution; no sustained recovery into rapid growth; recurrent external balance crises; and a need for sustained repression to hold the economic model's key policies in place.

\section{Fertility, Women and the Agenda for Action}

The Accelerated Development Report's treatment of population growth (ie its reduction) and of women in this and a more general context, is difficult to integrate into its general analytical themes and prescriptive clusters. Neither of these two interrelated questions is the topic of a paper in this Bulletin, but each requires attention.

The Report clearly includes reducing population growth as a crucial long term goal. While the somewhat simplistic neo-Malthusian case presented may grate on many readers, the argument that a 2.5 to 4 per cent annual increase in population would increase resource requirements for basic service and employment provision beyond those likely to be covered through any probable rate of output growth, is a compelling one.

What is less clear is the analysis of, or proposals for achieving demographic transition! Apparently the Report views this as an appropriate area for state intervention until the process of 'modernisation' itself takes over. Thus a number of rather secondary micro proposals are advocated. The Report, however, fails to address itself to the historic evidence that a decline in the birth rate usually follows lower death rates (especially infant mortality), which is related to more assured food supplies, access to pure water and education for the absolutely poor. The record suggests that the Report's proposals for reduced emphasis on basic services and its lack of explicit attention to distribution (which would almost certainly be worsened) or absolute poverty eradication (which would take time) would swamp any direct attempts to control fertility and prevent a decline in population growth."

As is all too usual in works of economic analysis, even when they do seek to articulate development targets and policies, women are semi-invisible and fragmented in the Report. They have not disappeared from view altogether, however. The education of women is recognised as a means of reducing population growth and of reducing the burden of household work (eg water and fuel collection, food processing). The latter is seen to be critical to raising agricultural production (though this point is not made in the chapter on agriculture).

These fragmentary references are not, however, related to the main body of argument. Overall the low priority attached to basic services, and proposals to introduce more charges for those that exist, run contrary to facilitating the contributions to development expected of women. There is no serious analysis of the specific roles women play in African economic structures - a defect which is particularly serious in respect to agriculture. The vision of the smallholder as 'African economic man' is simplistic. Even a coherent presentation of 'African economic woman' would, however, be welcome on analytical and operational as well as normative grounds.

\section{A Conclusion Advocating Dialogue}

The preceding view may seem highly critical. It is meant to be. Accelerated Development's political economic world view is incomplete, contentious and flawed. Therefore, its Agenda is not, taken by itself, a safe guide for action. Further, the Report's overly self confident style and tendency to instruct, rather than inform or advise, Africans and African leaders does not appear to be consistent either with its endorsement of participation, or with the reality that only Africans are primarily concerned with the well-being of Africa. They have the right to take basic decisions about their own destiny and can implement any agenda, whatever the logical force or external pressures toward its verbal acceptance may be.

\footnotetext{
"It is too alarmist and too cynical to suggest that they might raise mortality rates enoguh to cause African populations to revert to a high birth and death rate/low population growth pattern. In any event that could hardly be termed development, accelerated or otherwise.
} 
However, there is no intention to write off Accelerated Development as trivial, nor to fail to recognise the substantial validity of much of its analysis, many of its criticisms and a number of its proposals. It should not be denied its rightful status as a seriously researched and argued contribution to the dialogue on how most SSA states have sunk into economic stagnation or regression and what steps are necessary to halt these trends, consolidate a base for reversing them and begin to forge a new development dynamic. To do so would be either even more rigidly ideological than parts of the Report are, pedantically captious or blind.

A serious contribution to dialogue deserves a serious analysis. Because the Report is the first overall regional contribution, this is especially true in its case. Such a critique is the first step toward finding common ground, identifying areas of empirical or practical disagreement (at least in principle resolvable by reexamination of data and by dialogue), highlighting areas of risk and uncertainty and isolating areas in which the divergencies are on basic goods and value (in respect to which dialogue may identify costs and trade-offs as well as narrow divergencies but no universal, objective 'right' or 'wrong' answers exist). It is toward such a dialogue that this Bulletin seeks to contribute. Only after that stage can the process of modification, consideration of alternative overall approaches, evaluation of individual country strategies and moves towards medium term action be conducted on an informed basis. While some of the criticisms of the Agenda for Action in this Bulletin do imply alternative proposals, there is no attempt to present a systematic 'counter report'. To seek to do so would be presumptuous, premature and inappropriate, not least because the bulk of formal alternative proposals and, especially, of material action programmes should be the contribution of Africans in Africa - and preferably not just in offices in capital cities - not of Europeans in Europe - especially in well equipped universities. 